
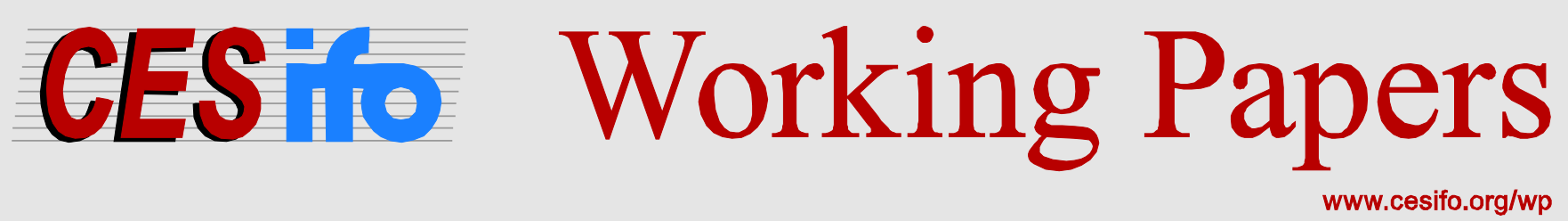

\title{
Convergence and Overtaking in a Dynamic Two Country Model
}

\author{
Partha Sen \\ Koji Shimomura
}
CESIFO WORKING PAPER NO. 6027
Category 8: Trade Policy
August 2016

An electronic version of the paper may be downloaded

- from the SSRN website:

- from the RePEc website:

- from the CESifo website:

www.SSRN.com

Www.RePEc.org

www.CESifo-group.org/wp 


\title{
Convergence and Overtaking in a Dynamic Two Country Model
}

\begin{abstract}
In two-sector infinite-horizon trade models with factor-price-equalization, convergence of aggregate capital-labor ratios and incomes does not occur because the Euler equations imply equal growth rate of consumption in all economies. In a two-country dynamic specific factors model, we show that factor-price-equalization occurs only in the long run. Per capita incomes and consumptions do not necessarily converge. These depend on the endowments of the primary factors. Depending on these endowments, an initially poorer economy may end up as the richer economy in the steady state, overtaking the initially richer one.
\end{abstract}

JEL-Codes: F110.

Keywords: convergence, specific factors, Euler equations.

Partha Sen

Centre for Development Economics

Delhi School of Economics

Delhi / India

partha@econdse.org
Koji Shimomura

RIEB

Kobe University

Kobe / Japan

(deceased)

July 2016

Koji Shimomura died in 2007. At the time this paper was in a very preliminary state. Previous versions of this paper were presented at seminars at INSEAD, Sciences Po, University of Kent and Bank of Portugal. Helpful comments came from Isabel Corriea, Antonio Fatas and Tim van Zandt. 


\section{INTRODUCTION}

The spectacular growth of the East Asian economies since the Second World War has focused attention on whether poorer economies catch-up with the more advanced ones over time-i.e. do economies at different stages of their growth process converge to similar or even the same steady state? Historically, of course, nations have grown quickly and often declined as quickly, late-comers have done well etc. A consensus reached in the literature seems to point to "conditional convergence"--economies with similar institutional, educational backgrounds etc. do exhibit convergence (see Barro and Sala-iMartin (2003)). If this is indeed the case then we may ask (as does Ventura (1997)): which model of economic growth is consistent with growth empirics (the conditional convergence cross-section story)? Initially the candidates available were mainly closed economy growth models: the (one-sector) Solow growth model or its optimizing version, the Ramsey-Cass-Koopmans model were the pack leaders. The question naturally arises as to whether these models can hope to shed light on the process of growth where international trade and factor movements were not a side activity but were centre-stage.

To see that the selection of the class of models makes a huge difference, note that in a one sector closed economy (Solow, Ramsey) a capital-rich advanced economy with a higher aggregate capital-labor ratio is necessarily one with a lower rate of return to capital. In an open economy two-sector model with incomplete specialization, on the other hand, an increase in the capital-labor ratio causes the economy's capital-intensive sector to expand (if it is a small open economy where the economy faces given factor and goods prices, the Rybczinski Theorem tells us that the labor-intensive sector would contract). Thus in an open economy, capital can be accumulated by a change in the product mix without a fall in the rate of return to capital. A whole range of capital-labor ratios (i.e. ratios in the cone of diversification) can coexist with any given rate of return to capital. In a two-sector model long run convergence of rental rates on capital does not imply convergence of capital-labor ratios and output. ${ }^{\mathrm{i}}$ 
The Heckscher-Ohlin-Samuelson (H-O-S) model is the basic work-horse of international trade theory (between dissimilar economies). ${ }^{\text {ii }}$ This notwithstanding the fact that it (deliberately) uses assumptions that fly in the face of reality (e.g. identical technologies, identical homothetic tastes etc.). Empirically, it has had a hard time justifying its pre-eminence. But trade theorists are loath to let it go, possibly because of the lack of an agreed tractable alternative.

In the last twenty years the H-O-S model has been extended to a dynamic setting with optimizing agents ${ }^{\mathrm{iii}}$. In this paper we shall concentrate on a subset of such models where agents are infinitely lived, and there is no international borrowing or lending. ${ }^{\text {iv }}$ In such a setting, $\mathrm{H}-\mathrm{O}-\mathrm{S}$ implies that if there is factor-price, there will be no convergence (in incomes and consumption per capita). In particular, with identical technologies, two mobile (across sectors) factors ${ }^{\mathrm{v}}$ and identical homothetic tastes, consumption growth is equal in all the economies at all times. To see this, note all the economies face the same rental rate on capital and have common depreciation rates as well as rates of time preference, thus their Euler equations predict equal consumption growth rates, independent of levels of initial consumption. Thus there is no convergence i.e. the initial differences in consumption never disappear (see Chen (1992), Atkeson and Kehoe (2000), Bajona and Kehoe (2006 and 2010), Chaterjee and Shukayev (2012); see also Baxter (1992), Bianconi (1995) and Kaneko (2006). ${ }^{\mathrm{vi}}$ The intuition for this result is that with factor-price-equalization, asset trade that was missing from the model (via the absence of borrowing and lending) is, in effect, achieved by commodity trade. The poorer economy is identical to the richer economy, except in its size and behaves like the latter. Hence both grow at the same rate and the poorer economy never catches up.

Is this then the end of the road for dynamic international trade models with identical technologies and tastes, but with differences in factor endowments? In the literature, the answer to this question seems to be in affirmative. There are a number of papers that try to address the twin concerns that H-O-S has had a hard time explaining trade flows and that conditional convergence is empirically observed. These papers (Ventura (1997, Bajona and Kehoe (2010), move away from identical technologies (trade 
now is based on Ricardian considerations) ${ }^{\mathrm{vii}}$. Another strand of the literature assumes that one country has an absolute advantage in both goods (via a higher Hicks-neutral term)see e.g. Brecher, Chen and Choudhri (2002), Chatterjee and Shukayev (2012)). It is well known that in a static setting only comparative advantage matters but in a dynamic setting absolute advantage (of the Hicks-neutral variety) can determine trade patterns. ${ }^{\text {vii }}$ Both these classes of models follow Trefler (1993) who argued that a different form of the factor-price-equalization theorem that allows for factor-augmenting international productivity differences is empirically consistent with observed cross- country variation in factor prices. Finally, the result has been shown to depend crucially on agents being infinitely lived-Sen (2015) shows that in a Blanchard-Yaari model, convergence indeed occurs.

Ventura (1997) had assumed that there was incomplete specialization and obtained conditional convergence. Bajona and Kehoe (2010) showed that if in a Venturatype model complete specialization is allowed, then there are other possibilities-e.g., that an economy could decumulate capital and specialize in the labor-intensive good in the new steady state. Atkeson and Kehoe (2000) had showed that a "late-comer" small open economy specializing in the labor-intensive consumption good, accumulates capital until it reaches the (lowest) capital-labor ratio of the world economy (the latter is assumed to be in a steady-state).

In this paper we take a different tack. We want to stay within the tradition of factor endowments determining trade in a model with identical homothetic tastes. We propose a dynamic specific factors model. There are three factors of production, two goods and identical technologies and identical homothetic preferences. Thus the break from the literature cited above is the introduction of an additional factor, with two factors now being specific to sectors and one mobile across sectors. We will show that in such a framework the world economy converges to unique steady state with factor-price equalization (the zero-root problem disappears) and in both countries techniques of production are identical. Incomes and consumption may not converge in the long run, however. Outside the steady state there is no factor-price equalization, although the two 
economies are always incompletely specialized. Finally, we show that late-comers may overtake “early-bloomers”.

The specific factors model (also known as the Ricardo-Viner model), though not as popular as the H-O-S model, is still an important enough model whose dynamic behavior warrants more attention than it has received hitherto. It has a long history (starting with Ricardo). Jones (1971) revived this literature; this was because of the observation that the Stolper-Samuelson theorem gave predictions on protection that seemed to fly in the face of casual empiricism-namely, in any sector the interests of labor and capital are implacably opposed to one another. The specific factors model, on the other hand, suggests (some) convergence of interest among all factors in the industry demanding protection. Add to this the fact that in the early empirical implementation of the Heckscher-Ohlin model (the Leontief Paradox), there was a feeling that the twofactor framework was too much of a straitjacket (and land needed to be added as a third factor). In any case, empirically any dynamic model that is grappling with the issue of convergence (or lack of it) cannot ignore the importance of land as a factor of production, at least in the initial stages of development. ${ }^{\text {ix }}$ Therefore it is our belief that the specific factors model deserves a detailed analysis in its dynamic version in an infinitely-lived agent set-up. In this paper we do precisely this and study the issue of convergence in a two-country dynamic version of this model.

There are quite a few dynamic models with infinitely-lived agents and specific factors. Eaton ((1987) (1988)) was the first model specific factors in a dynamic setting (in a two period overlapping generations framework with a small country and capital mobility). Brock and Turnovsky (1993) looked at a small country model with infinitelylived agents and capital mobility. More recently there are the contributions of $\mathrm{Hu}$, Nishimura and Shimomura ((2006), (2008)) and Sen (2013). ${ }^{\mathrm{x}}$

There are other models that point to the inadequacy of factor endowments in explaining international trade. Unions, culture and demographic shocks are examples of these. Some can be accommodated in the specific factors set-up with a minor tweak, 
while others would require a lot more work. ${ }^{x i}$ Giving the specific factors model this interpretation would help us empirically verify these models. ${ }^{\text {xii }}$

\section{THE MODEL}

Dynamic international trade models with infinitely-lived agents come in three different types. The first modified the closed economy two-sector model with two goods-one pure consumption and the other pure investment good-making both goods tradable. ${ }^{\text {xiii }}$ In the second type, like the popular endogenous growth model (with R\&D and monopolistically competitive intermediate-goods sector), there are models with two traded intermediate goods that produce a final good. ${ }^{\text {xiv }}$ This final good can be used either for consumption or investment. Finally, there is a literature based on Komiya (1967) and Findlay (1995) has two traded consumption goods and a non-traded investment good that is produced by combining the two consumption goods. ${ }^{\mathrm{xv}}$

In our model we follow the second tradition mentioned above and have two traded intermediate goods that produce a final good that can be consumed or invested. In this section, capital is the mobile factor between sectors and can be accumulated, whereas the other two factors are inelastically supplied and are specific to sectors. Technology and tastes are identical across countries. There is no international borrowing or lending. Agents have perfect foresight. In the next section we discuss two modifications to the model outlined in this section.

\subsection{The Momentary Equilibrium}

In each of the two economies (called home and foreign, with foreign variables denoted by an asterisk), two intermediate goods ( $\mathrm{X}$ and $\mathrm{Y}$ ) are produced using three factors of production (K, L and M). Capital $\mathrm{K}$ is mobile across sectors, whereas ${ }^{\mathrm{xv}} \mathrm{L}$ and $\mathrm{M}$ are specific to sectors $\mathrm{X}$ and $\mathrm{Y}$ respectively. ${ }^{\text {xvii }}$

$$
X=F\left(K^{x}, \bar{L}\right)
$$


$X^{*}=F\left(K^{x^{*}}, \overline{L^{*}}\right)$

$\mathrm{F}$ is increasing in its arguments and homogeneous of degree one in the two inputs and is twice continuously differentiable. Both inputs are essential for production. It also satisfies the Inada conditions--for capital it implies that it would be employed in both sectors. We have (a subscript denotes a partial derivative):

$F(0, L)=F(K, 0)=0$

$i \rightarrow 0, F_{i}(.) \rightarrow \infty \quad i=K, L$

$i \rightarrow \infty, F_{i}(.) \rightarrow 0$.

The $\mathrm{Y}$ good is also produced via a linear-homogeneous technology $G($.$) that$ satisfies positive but diminishing marginal products for factors. Essentiality of inputs, twice continuous differentiability and Inada conditions similar to F hold.

$Y=G\left(K^{y}, \bar{M}\right)$

$Y^{*}=G\left(K^{y^{*}}, \bar{M}^{*}\right)$

Full employment for L and M has been implicitly assumed by putting bars on top of the variables. For capital we have,

$$
\begin{aligned}
& K=K^{x}+K^{y} \\
& K^{*}=K^{x^{*}}+K^{y^{*}}
\end{aligned}
$$

We assume that the levels of the specific factors are constant. ${ }^{\text {xviii }}$ We also assume that the economies are "different"--their ratios of specific factors are different across countries i.e. 
Intermediate inputs are traded internationally and used to produce a homogeneous good, Q. This good can be used either for consumption or capital accumulation. Trade in the intermediate inputs requires (a variable with a tilde denotes the quantity demanded of the intermediate input):

$$
\begin{aligned}
& X+p Y=\tilde{X}+p \tilde{Y} \\
& X^{*}+p Y^{*}=\tilde{X} *+p \tilde{Y}^{*}
\end{aligned}
$$

The $\mathrm{X}$ good is the numeraire and $\mathrm{p}$ is the (free trade) relative price of the Y good. Note that we have assumed that trade is balanced, i.e. there is no borrowing or lending.

The final good is produced by the following technology:

$$
\begin{aligned}
& Q=H(\tilde{X}, \tilde{Y}) \\
& Q^{*}=H\left(\tilde{X}^{*}, \tilde{Y}^{*}\right)
\end{aligned}
$$

The function $\mathrm{H}($.$) is also increasing, homogeneous of degree one in its arguments, is$ twice continuously differentiable and satisfies the Inada conditions.

The final good can be consumed or invested:

$$
\begin{aligned}
& Q(t)=C(t)+I(t) \\
& Q^{*}(t)=C^{*}(t)+I^{*}(t)
\end{aligned}
$$

We define the GDP function

$$
R(1, p, K) \equiv \max _{K^{x}, K^{y}}\left\{F\left(K^{x}, \bar{L}\right)+p G\left(K^{y}, \bar{M}\right) \mid K^{x}+K^{y}=K\right\}
$$


$R^{*}\left(1, p, K^{*}\right) \equiv \max _{K^{x^{*}}, K^{\mu^{*}}}\left\{F\left(K^{x^{*}}, \bar{L}^{*}\right)+p G\left(K^{y^{*}}, \bar{M}^{*}\right) \mid K^{x^{*}}+K^{y^{*}}=K^{*}\right\}$

We have from the above:

$$
\begin{aligned}
& F_{K}\left(K^{x}, \bar{L}\right)=p G_{K}\left(K-K^{x}, \bar{M}\right) \\
& F_{K}\left(K^{x^{*}}, \bar{L}^{*}\right)=p G_{K}\left(K^{*}-K^{x^{*}}, \bar{M}^{*}\right)
\end{aligned}
$$

Thus, given the capital stock in each economy and the relative price, capital moves across the sectors till its marginal revenue product is equalized. ${ }^{\mathrm{xix}}$

The final good $(\mathrm{Q})$ is an assembly of the two inputs procured in international markets by trading the GDP of the economy in question. The relative price of $\mathrm{Q}$ is $\mathrm{z}$ (in terms of the numeraire). The price $\mathrm{z}$ is linearly-homogeneous in the prices of the inputs (1 and p) - it is the unit cost of producing Q. Since both economies face the same input prices (and have the same technology), $\mathrm{z}$ is identical across the two countries.

Momentary (or short-run) equilibrium in the world economy (i.e. given the state variables $K(t)$ and $\left.K^{*}(t)\right)$ requires that the value of the final good be equal to the GDP of the respective economies and that the markets for the two inputs clear. ${ }^{\mathrm{xx}}$ These conditions are given by equations (18), (19) and (20).

$$
\begin{aligned}
& z(1, p) Q=R(1, p, K) \\
& z(1, p) Q^{*}=R^{*}\left(1, p, K^{*}\right)
\end{aligned}
$$

In addition to the above two budget constraints, we must ensure that the markets for the two traded goods clear. By Walras' Law if one of the markets clear, then so does the other one. The market-clearing condition for the $\mathrm{Y}$ good is:

$$
R_{p}+R_{p}^{*}=\left(Q+Q^{*}\right) Z_{p}
$$




\subsection{Capital Accumulation and Dynamics}

The two countries have identical homothetic tastes. In particular, the rate of time preference is identical across countries. Agents possess perfect foresight. The representative consumer maximizes the following utility functional (a similar specification holds for the foreign country):

$$
\int_{0}^{\infty}[u(C(t)) \exp \cdot(-\rho t)] d t
$$

where $\rho$ is the rate of time preference. The instantaneous utility function $\mathrm{u}($.$) satisfies$ $u^{\prime}(C)>0, u^{\prime \prime}(C)<0, u^{\prime}(C)_{c \rightarrow 0} \rightarrow \infty$, and $u^{\prime}(C)_{c \rightarrow \infty} \rightarrow 0$.

The accumulation equations are given by ${ }^{\mathrm{xxi}}$

$$
\begin{aligned}
& \dot{K}(t)=Q(t)-\delta K(t)-C(t) \\
& \dot{K}^{*}(t)=Q^{*}(t)-\delta K^{*}(t)-C^{*}(t)
\end{aligned}
$$

There is an initial condition on each of the capital stocks:

$$
\begin{aligned}
& K(0)=K_{0}, \\
& K^{*}(0)=K_{0}^{*} .
\end{aligned}
$$

and tranversality conditions for the two economies:

$\lim _{t \rightarrow \infty} K(t) \cdot u^{\prime}(C(t))$. exp. $(-\rho t)=0$

$\lim _{t \rightarrow \infty} K^{*}(t) \cdot u^{\prime}\left(C^{*}(t)\right)$. exp. $(-\rho t)=0$. 
We set up the maximization problem for the representative household in the domestic economy. The household takes the time path of $\mathrm{p}$ as given and maximizes the following current-value Hamiltonian ( $\mu$ is the co-state variable):

$\Omega \equiv u(C)+\mu[\{R(1, K, p) / z(1, p)\}-\delta K-C]$

The necessary optimality conditions are:

$$
\begin{aligned}
& u^{\prime}(C)=\mu \\
& \dot{\mu}=\left\{(\rho+\delta)-\left(R_{K} / z\right)\right\} \mu
\end{aligned}
$$

and $\lim _{t \rightarrow \infty} K(t) \cdot u^{\prime}(C(t))$. exp.(- $\left.\rho t\right)=0 \quad$ (equation (24a) above).

Substituting (26) in (27) (and differentiating with respect to time), along the optimal path we have the Euler equations (with $\sigma \equiv-u^{\prime \prime}(C) C / u^{\prime}(C)$ )

$\dot{C}(t) / C(t)=\sigma^{-1}(r(t)-(\rho+\delta))$,

Similarly for the foreign country we have:

$\dot{C}^{*}(t) / C^{*}(t)=\sigma^{-1}\left(r^{*}(t)-(\rho+\delta)\right)$.

Along a competitive equilibrium path, households in both countries choose optimal paths for consumption and investment (and hence capital stocks), taking the path of prices of factors and goods as given. Firms take the path of factor prices and goods prices as given and maximize their profits. The resulting optimal production and consumption decisions satisfy the market-clearing conditions.

We now turn to the steady state of the model. 


\subsection{The Steady State}

There is a trivial steady state with $\bar{K}=\bar{K}^{*}=\bar{C}=\bar{C}^{*}=0$ (an overbar on an endogenous variable denotes its steady state magnitude). The non-trivial steady state of the model is given by setting the time derivatives in equations (22a), (22b), (28a) and (28b) to zero. We thus have:

$$
\begin{aligned}
& \bar{R}_{K} / \bar{Z}=(\delta+\rho) \\
& \bar{R}_{K}^{*} / \bar{Z}=(\delta+\rho) \\
& \bar{Q}-\delta \bar{K}=\bar{C} \\
& \bar{Q}^{*}-\delta \bar{K}^{*}=\bar{C}^{*}
\end{aligned}
$$

From the properties of the GDP functions and the price indices, equations (29a) and (29b) solve uniquely for the steady state capital stocks $\bar{K}$ and $\bar{K}^{*}$. Given these

equations (29c) and (29d) determine the unique values of steady state levels of $\bar{C}$ and $\bar{C}^{*}$. Thus the nontrivial steady state is unique.

From equation (29a) and (29b) we see that in the steady state rates of return are equalized. From the linear homogeneity of F(.) and G(.), so are returns to L and M (these depend only on the ratios of $\mathrm{K}^{\mathrm{x}}$ to $\mathrm{L}$ and $\mathrm{K}^{\mathrm{y}}$ to $\mathrm{M}$ ).

We thus have:

\section{Proposition 1: In the steady state we have factor-price equalization.}

\subsection{Dynamics}

The behavior of the world economy over time can be represented by the four differential equations given by (22a), (22b), (28a) and (28b). 
Linearizing these four differential equations around the initial steady state and writing in a matrix form, we have: ${ }^{x x i i}$

$$
\left[\begin{array}{l}
\dot{C} \\
\dot{C}^{*} \\
\dot{K} \\
\dot{K}^{*}
\end{array}\right]=\left[\begin{array}{cccc}
0 & 0 & z^{-1}\left\{R_{K K}-\left(\theta_{\tilde{X} Q} R_{K} / p\right) p_{K}\right\} & -z^{-1}\left(\theta_{\tilde{X} Q} R_{K} / p\right) p_{K^{*}} \\
0 & 0 & -z^{-1}\left(\theta_{\tilde{X} Q} R_{K^{*}} / p\right) p_{K} & z^{-1}\left\{R_{K^{*} K^{*}}^{*}-\left(\theta_{\tilde{X} Q} R_{K^{*}} / p\right) p_{K^{*}}\right\} \\
-1 & 0 & Q_{K}-\delta & Q_{K^{*}} \\
0 & -1 & Q_{K}^{*} & Q_{K^{*}}^{*}-\delta
\end{array}\right]\left[\begin{array}{l}
C-\bar{C} \\
C^{*}-\overline{C^{*}} \\
K-\bar{K} \\
K^{*}-\overline{K^{*}}
\end{array}\right]
$$

Or compactly:

$\dot{V}=A(V-\bar{V})$

where $\mathrm{V} \equiv\left[\mathrm{C}, \mathrm{C}^{*}, \mathrm{~K}, \mathrm{~K}^{*}\right]^{\mathrm{T}}$.

Det. $A=z^{-2}\left[R_{K K} R_{K^{*} K^{*}}^{*}+R_{K K}\left\{\left(\theta_{\widetilde{X} Q} R_{K^{*}} / p\right) p_{K^{*}}\right\}+R_{K^{*} K^{*}}^{*}\left\{\left(\theta_{\widetilde{X} Q} R_{K} / p\right) p_{K}\right\}\right]$

$=Z^{-2}\left\{R_{K K} R_{K^{*} K^{*}}^{*}+\left(R_{K K}+R_{K^{*} K^{*}}^{*}\right)\left(\theta_{\tilde{X} Q} R_{K} / p\right) p_{K}\right\}$

$=z^{-2}\left[R_{K K} R_{K^{*} K^{*}}^{*}+\left\{\left(R_{K K}+R_{K^{*} K^{*}}^{*}\right)\left(R_{K} \theta_{\tilde{X} Q}\right)^{2}\left(b_{32} p^{2}\right)^{-1}\right\}\right]>0$

$\operatorname{Tr} . A=Q_{K}+Q_{K^{*}}^{*}-2 \delta=2\left(R_{K}-\delta\right) / z=2 \rho / z>0$

$\Sigma_{2 \times 2}=Q_{K} Q_{K^{*}}^{*}-Q_{K^{*}} Q_{K}^{*}+\delta^{2}-\left(Q_{K}+Q_{K^{*}}^{*}\right) \delta$

$=Z^{-2}\left[\left\{J^{y}\left(d p / d K^{*}\right)+R_{K^{*}}^{*}\right\}\left\{-J^{y}(d p / d K)+R_{K}\right\}-\left\{J^{y}\left(d p / d K^{*}\right)\right\}\left\{-J^{y}(d p / d K)\right\}\right]$

$-\delta Z^{-1}\left\{J^{y}\left(d p / d K^{*}\right)+R_{K^{*}}^{*}-J^{y}(d p / d K)+R_{K}\right\}+\delta^{2}$

$=\left(-2 z^{-1} R_{K}+\delta\right) \delta<0$

(In the above expressions, $\mathrm{J}^{\mathrm{y}}$ is the import of the $\mathrm{y}$-good by the home country. The value of $b_{32}$ is given in Appendix A) 


\section{Proposition 2: Matrix A has two "stable" roots and two "unstable" roots. Hence, the long-run equilibrium is a saddle-point.}

Proof: The determinant of the coefficient matrix $\mathrm{A}$ is positive. This implies one of the following possibilities: (i) that there are four unstable roots i.e. with positive real parts (if complex conjugates); (ii) four stable roots i.e. with negative real parts (if complex conjugates); and (iii) two unstable roots (with positive real parts) and two stable (with negative real parts). Note that the positive value of the determinant rules out the possibility of a zero root (or hysteresis). The trace is positive, thereby ruling out all negative roots (possibility (ii)). The sum of the product of two roots at a time $\left(\sum_{2 \times 2}\right)$, is negative, so all the roots cannot be positive. We are then left with possibility (iii) i.e., exactly two negative roots (or with negative real parts). The steady state is therefore a saddle-point and the stable arm is a plane. Since there are two predetermined variables (K and $\mathrm{K}^{*}$ ), and two forward-looking (or “jump”) variables (C and $\mathrm{C}^{*}$ ), we can associate an initial condition with each of the stable roots. The two transversality conditions rule out explosive behavior due to unstable roots.

\subsection{Steady State per Capita Income and Consumption}

We showed in Proposition 1 that in the steady state there is international equalization of the returns to all the factors of production. But what about the behavior of consumption and investment per capita? Do these converge?

If we think of input $\mathrm{L}$ as labor and $\mathrm{M}$ as fruits (the fact fruit trees or land are durable is discussed in the next section-here just think of $\mathrm{M}$ as a non-labor primary input and look at its steady state implications). We find that differences in the endowment

of the factor of production, $\mathrm{M}$, determines differences in per capita consumption. Since the two economies are assumed different in the ratios of $\mathrm{M} / \mathrm{L}$, the economy with a higher $\mathrm{M} / \mathrm{L}$ ratio will have higher consumption and investment (equal to the depreciation of the capital stock). Capital in the steady state is "obtainable" at a fixed price of $\bar{z}(\delta+\rho)$. 
Thus the economy with a higher $\mathrm{M} / \mathrm{L}$ ratio will have more capital per capita so that the ratio of capital to land in the Y sector is also equalized internationally. We have then (we drop the overbars on $\mathrm{M}$ and $\mathrm{L}$ - these are in fixed supply throughout this paper):

$$
z(\bar{p})\{(\bar{C} / L)+\delta(\bar{K} / L)\}=f\left(\bar{K}^{x} / L\right)+p \cdot g\left(\bar{K}^{y} / M\right) \cdot(M / L)
$$

In equation (32), $\mathrm{f}($.$) and \mathrm{g}($.$) are respectively the per capita output in the \mathrm{X}$ sector and per unit of land output in the Y sector. From factor price equalization, $f($.$) and g($.$) are$ equalized internationally. Hence per capita income depends solely on the ratio M/L. We then have:

\section{Proposition 3: The economy with a higher per capita availability of $M$ has higher income, consumption and investment in the steady state.}

Comment: Only if the per capita land endowment is the same across economies, is it the case that (presumably starting from different capital stocks) will the economies converge to identical income, consumption and investment per capita.

\subsection{Behavior outside the Steady State}

It is straightforward to show that the higher capital-stock economy will have a lower rate of return to capital. The proof of this follows from the property of the GDP function-- $R_{K K}=F_{K K}<0$.

Why this should be so with the two economies having different endowments of the two specific factors is not apparent at first sight. That is, in a three factor model, how do we define a capital-poor economy? The solution lies in comparing the marginal products in the two sectors across economies. This gives us (from equations (16) and (17) and using linear homogeneity of $F($.$) and G()$.$) :$

$$
f^{\prime}\left(K^{x} / L\right) / f^{\prime}\left(K^{x^{*}} / L^{*}\right)=g^{\prime}\left(K^{y} / M\right) / g^{\prime}\left(K^{y^{*}} / M^{*}\right)
$$


Equation (33) tells that no matter what the initial distribution of the specific factors internationally, equalization of marginal products for the mobile factor and international goods prices, ensures that an economy with a relatively high (low) ratio of capital employed per worker in the $\mathrm{X}$ sector will also have a relatively high (low) ratio of capital per unit of land in the $\mathrm{Y}$ sector.

Now it is easy to show that the capital poor economy will have a higher growth of consumption per capita. We use the inverse relationship between the marginal product of capital and the economy's capital stock in equations (27) and (28) (remembering that $\left.r(t)=[z(p(t))]^{-1} f^{\prime}\left(K^{x}(t) / L\right)\right)$

$$
\dot{C}(t) / C(t)-\dot{C}^{*}(t) / C^{*}(t)=\sigma^{-1}\left(r(t)-r^{*}(t)\right)
$$

Equation (33) assures us that the capital-rich country will have a lower interest rate. Hence in (34) the capital-poor country will grow faster. We summarize this in:

\section{Proposition 4: Outside the steady state, an economy with a lower stock of capital per capita will have a higher interest rate and a higher growth rate of consumption per capita compared to an economy with a higher capital stock per capita.}

\section{EXTENSIONS}

\subsection{Extension 1: Labor as the mobile factor}

How does the analysis in the previous section change if instead of capital (the factor that can be accumulated), it is labor (one of the factors in given supply) that were mobile? This was the structure, albeit in a two period overlapping generations model, of Eaton (1987), (1988). Suppose X is produced using labor and capital, and Y uses labor and the other factor $(\mathrm{M})$. That is: 


$$
\begin{aligned}
& X(t)=F\left(L^{x}(t), K(t)\right) \\
& Y(t)=G\left(L-L^{x}(t), M(t)\right)
\end{aligned}
$$

In the model now,

$$
R(1, p, K) \equiv \max _{L^{x}, L^{y}}\left\{F\left(L^{x}, K\right)+p G\left(L^{y}, \bar{M}\right) \mid L^{x}+L^{y}=L\right\}
$$

Now the marginal product of labor is equalized across sectors;

$$
F_{L}(.)=p G_{L}(.)
$$

How does the dynamic analysis change? Algebraically, it does not change very much. In particular, conditions (31a), (31b) and (31c) are exactly the same as in the previous case. The derivatives in Appendix A are modified, though-these are given in Appendix B.

The dynamics of capital accumulation in either country is accompanied by labor moving to the $\mathrm{X}$ sector. As this happens, an excess demand for the $\mathrm{Y}$ good arises that raises p. ${ }^{\text {xiii }}$ This slows down the drain of labor from the Y sector.

The steady state is still given by equations (29a), (29b) and (29c) except that we note in (31a), we have $\bar{R}_{K}\left(=\bar{X}_{K}\right)=\bar{z}(\delta+\rho)$.

In the model of section 2, a higher land endowment calls forth higher capital accumulation. Loosely speaking, across steady states land and capital are complements. In the example of this section, land and capital are substitutes. A high land endowment per capita implies a higher wage rate and a lower capital stock. This is because the rental rate is driven down "very quickly" to its steady state value. ${ }^{\text {xxiv }}$ 
Note that the two cases studied so far (in Section 2 and in this sub-section) exhaust all the possible cases of the specific factors model in a dynamic setting (this is true as long as both $\mathrm{L}$ and $\mathrm{M}$ are inelastically supplied).

\subsection{Extension 2: Durable land as a fixed factor}

In this second example, let us go back to the original model, with capital being mobile across the sectors (the analysis below holds for labor being mobile across the sectors also). The production functions for the two goods are given by (as in section 2):

$$
\begin{aligned}
& X=F\left(K^{x}, L\right) \\
& Y=G\left(K^{y}, M\right)
\end{aligned}
$$

Now suppose $\mathrm{M}$ is land whose supply is inelastically given. Land is a durable asset with a price (in terms of the numeraire) of q. Arbitrage between the return to capital and land requires (assume land does not depreciate):

$$
\left(R_{K}-z \delta\right)=\left(p Y_{M}+\dot{q}\right) / q
$$

The return to land in (38a) consists of its marginal product and the capital gains.

Similarly for the foreign economy:

$$
\left(R_{K^{*}}^{*}-z \delta\right)=\left(p Y_{M^{*}}^{*}+\dot{q}^{*}\right) / q^{*}
$$

Solving the differential equations in (38a) and (38b) and imposing transversality conditions, we find that the price of land is given by the present discounted value of the marginal product of land, where the (time-varying) discount factor is the return to capital. 


$$
\begin{gathered}
q(t)=\int_{t}^{\infty} e^{-\int_{t}^{s}\left[R_{K}(v)-\delta z(v)\right] d v} p(s) Y_{M}(s) d s \\
q^{*}(t)=\int_{t}^{\infty} e^{-\int_{t}^{s}\left[R_{K}^{*}(v)-\delta z(v)\right] d v} p(s) Y_{M}^{*}(s) d s
\end{gathered}
$$

Now in our model the dynamics of the world economy can be characterized by the system given in (30) and the two land price differential equations (39a) and (39b) (the analysis of the dynamics can be obtained from the authors on request).

\section{COMMODITY AND FACTOR PRICES IN AND OUTSIDE THE STEADY STATE: DISCUSSION}

We have analyzed the dynamics and the steady state behavior of the specific factors model. While convergence of factor prices is assured, incomes do not converge. What about the dynamic behavior of factor prices? I briefly review the differences between our model and the other models with infinitely-lived agents and trade.

First, note that in our model there is incomplete specialization-both countries produce both goods. If full employment is assumed for the specific factors, issues of diversification that are important in the $\mathrm{H}-\mathrm{O}-\mathrm{S}$ framework, do not arise here. For example, in the first model the entire plane with $\mathrm{L}$ and $\mathrm{M}$ on the axes is the cone of diversification. In either sector, full employment of the fixed factor requires some capital - we have assumed both factors are essential for production-and initially capital flows to a sector because of the Inada condition. Hence both economies would produce both goods and (mobile) capital would be employed in both sectors. Thus both the economies are incompletely specialized. Even if, contrary to our assumption, capital were not essential for the production of the traded intermediate goods, market-clearing for the specific factors (with positive marginal products) would ensure strictly positive outputs in these sectors. 
Second, international trade under competitive conditions would equalize goods prices. In our model only the intermediate goods are traded and their prices are equalized. In the H-O-S set up, this would imply that all factor prices are equalized in the cone of diversification. This is because with two factors of production, in both countries, we have ( $\mathrm{k}^{\mathrm{i}}$ is the capital-labor ratio in sector $\mathrm{i}$ )

$$
\begin{aligned}
& f^{\prime}\left(k^{x}\right)=p \cdot g^{\prime}\left(k^{y}\right) \\
& f\left(k^{x}\right)-k^{x} f^{\prime}\left(k^{x}\right)=p \cdot\left[g\left(k^{y}\right)-k^{y} g^{\prime}\left(k^{y}\right)\right]
\end{aligned}
$$

Given $\mathrm{p}$, the above equations determine $\mathrm{k}^{\mathrm{x}}$ and $\mathrm{k}^{\mathrm{y}}$ and the returns to factors depend on these capital intensities. This is the celebrated "factor-price-equalization" result. As noted above, in a dynamic optimal growth framework this results in hysteresis-i.e. non-convergence. A country with a higher income has the same growth rate of consumption per capita as its poorer trading partner, implying thereby that the initial discrepancy in consumption levels is never eliminated. In effect, trade in goods also makes up for the lack of asset market integration.

In our dynamic specific factors model, there is (as noted above) factor price equalization only in the steady state. The discount rate ties down the net marginal product of capital in one of the sectors. But mobile capital across sectors ensures that the other marginal product also gets tied down. There are two factor intensities and they are uniquely determined by $p$ and $\rho+\delta$. We have (for the model of section 2 ):

$$
\begin{aligned}
& \bar{z}(1, p) \cdot(\rho+\delta)=F_{K}\left(\bar{K}^{x}, L\right)=p G_{K}\left(\bar{K}-\bar{K}^{y}, M\right) \\
& \bar{z}(1, p) \cdot(\rho+\delta)=F_{K}\left(\bar{K}^{x^{*}}, L^{*}\right)=p G_{K}\left(\bar{K}^{*}-\bar{K}^{y^{*}}, M^{*}\right)
\end{aligned}
$$

Finally, a comment on the difference in the "catch-up" possibilities in this model and the dynamic Heckscher-Ohlin model. If we think of a model with a bloc of a large number of richer economies in steady state, and a small economy still accumulating capital. In the example of Atkeson and Kehoe (2000), the poorer economy would 
accumulate capital while completely specialized in the labor-intensive good. This continues until it reaches the minimum capital-labor ratio of the richer bloc consistent with factor price equalization. Its capital accumulation ceases here because the (net) return to capital equals the rate of time preference. Thus while factor prices are equalized, its income per capita never reaches the level of any richer country (save those that are also the most labor-abundant among them). So a poorer economy grows richer, while the rich remain in steady state, but they never quite catch up. In Bajona and Kehoe (2006), it is shown that in an overlapping generations structure, economies converge to the same capital labor-ratio. In our model (of section 2), it is possible that the richer land per capita economy starts of being poorer in terms of income (because of a very low capital stock initially) but then overtakes the other one before settling down as the richer economy in steady state. Thus there is the possibility of catch-up and overtaking by the late-comer in the specific factors model.

\section{CONCLUSIONS}

We showed that there is convergence (in factor prices) in a dynamic specific factors model with two primary factors of production and without international borrowing or lending. Only in the steady state is there equalization of factor prices. Per capita incomes and consumptions do not get equalized if the two economies have different endowment ratios of the primary factors per capita. Outside the steady state there is no factor price equalization. This happens even though the economies produce both goods. Contrast this with the H-O-S model where, incomplete specialization implies factor-price equalization.

Our results should be seen to be suggesting that factor endowment models generally can give sensible conclusions in a growth context. It is only in an identicaltechnologies-two-factors scenario that we do not get convergence. 
In addition, we have shown that it is possible that the initially richer economy remains richer forever, or it may lose the race in per capita income terms to an initially poorer economy.

\section{APPENDIX A}

Totally differentiating equations (19), (20) and (21) we get equations (A1), (A2) and (A3) below. Written in matrix form we get (A.4). Equation (A5) is the positive because $b_{32}$ (in the coefficient matrix $B$ in equation (A4) below) is the partial derivative of excess demands with respect to price.

$$
\begin{aligned}
& z d Q+\left(Q z_{p}-R_{p}\right) d p=R_{K} d K \\
& z d Q^{*}+\left(Q^{*} z_{p}^{*}-R_{p}^{*}\right) d p=R_{K^{*}}^{*} d K^{*} \\
& z_{p}\left(d Q+d Q^{*}\right)-\left(R_{p p}+R_{p p}^{*}\right) d p=R_{p K} d K+R_{p K^{*}}^{*} d K^{*} \\
& {\left[\begin{array}{ccc}
z & \left(Q z_{p}-R_{p}\right) & 0 \\
0 & \left(R_{p}-Q z_{p}\right) & z \\
z_{p} & b_{32} & z_{p}
\end{array}\right]\left[\begin{array}{c}
d Q \\
d p \\
d Q^{*}
\end{array}\right]=\left[\begin{array}{c}
R_{K} d K \\
R_{K} d K^{*} \\
0
\end{array}\right]}
\end{aligned}
$$

Or compactly B.Z=S

$$
\begin{aligned}
& b_{32}=-\left(R_{p p}+R_{p p}^{*}\right)<0 \\
& \Delta=-b_{32} z^{2}>0 \\
& d Q / d K=\left\{\left(Q z_{p}-R_{p}\right)\left(z R_{p K}-R_{K} z_{p}\right)-z R_{K} b_{32}\right\} / \Delta=z^{-1}\left\{-J^{y}(d p / d K)+R_{K}\right\} \\
& d Q / d K^{*}=\left(Q z_{p}-R_{p}\right)\left(z R_{p K^{*}}^{*}-R_{K^{*}}^{*} z_{p}\right) / \Delta=-\left(J^{y} Z^{-1}\right)\left(d p / d K^{*}\right) \\
& d p / d K^{*}=-z\left(z R_{p K^{*}}^{*}-R_{K^{*}}^{*} z_{p}\right) / \Delta=R_{K}\left(1-p z_{p} z^{-1}\right) /\left(p b_{32}\right)=R_{K} \theta_{\tilde{X} Q} /\left(p b_{32}\right)<0 \\
& d p / d K=-Z\left(z R_{p K}-R_{K} z_{p}\right) / \Delta=R_{K}\left(1-p z_{p} z^{-1}\right) /\left(p b_{32}\right)=R_{K} \theta_{\tilde{X} Q} /\left(p b_{32}\right)<0 \\
& d Q * / d K=\left(R_{p}-Q z_{p}\right)\left(z R_{p K}-R_{K} z_{p}\right) / \Delta=z^{-1} J^{y}(d p / d K)
\end{aligned}
$$


$d Q^{*} / d K^{*}=\left\{-\left(Q z_{p}-R_{p}\right)\left(z R_{p K^{*}}^{*}-R_{K^{*}}^{*} z_{p}\right)-z R_{K^{*}}^{*} b_{32}\right\} / \Delta=z^{-1}\left\{J^{y}\left(d p / d K^{*}\right)+R_{K^{*}}^{*}\right\}$

\section{APPENDIX B}

In Appendix A, the values obtained in equations (A6a) to (A6f) are modified to:

$$
\begin{aligned}
& d Q / d K=\left\{\left(Q z_{p}-R_{p}\right)\left(-R_{K} z_{p}\right)-z R_{K} b_{32}\right\} / \Delta=z^{-1}\left\{-J^{y}(d p / d K)+R_{K}\right\} \\
& d Q / d K^{*}=\left(Q z_{p}-R_{p}\right)\left(-R_{K^{*}}^{*} Z_{p}\right) / \Delta=-\left(J^{y} Z^{-1}\right)\left(d p / d K^{*}\right) \\
& d p / d K^{*}=z\left(R_{K^{*}}^{*} z_{p}\right) / \Delta>0 \\
& d p / d K=z\left(R_{K} z_{p}\right) / \Delta>0 \\
& d Q^{*} / d K=\left(R_{p}-Q z_{p}\right)\left(-R_{K} z_{p}\right) / \Delta=z^{-1} J^{y}(d p / d K) \\
& d Q^{*} / d K^{*}=\left\{\left(Q z_{p}-R_{p}\right)\left(R_{K^{*}}^{*} z_{p}\right)-z R_{K^{*}}^{*} a_{32}\right\} / \Delta=z^{-1}\left\{J^{y}\left(d p / d K^{*}\right)+R_{K^{*}}^{*}\right\}
\end{aligned}
$$

\section{REFERENCES}

Atkeson, Anthony, and Patrick J. Kehoe (2000) "Paths of Development for Early- and Late-boomers in a Dynamic Heckscher-Ohlin Model,” Research Staff Report No. 256, Federal Reserve Bank of Minneapolis.

Arnold, Lutz G. and Stefanie Trepl (2015) “A North-South Trade Model of Offshoring and Unemployment," Open Economies Review 265, 999-1039.

Bajona, Claustre and Timothy J. Kehoe (2006) "Demographics in Dynamic HeckscherOhlin Models: Overlapping Generations versus Infinitely Lived Consumer,” Research Staff Report No. 377, Federal Reserve Bank of Minneapolis.

--------(2010) "Trade, Growth, and Convergence in a Dynamic Heckscher-Ohlin Model,” Review of Economic Dynamics 13, 487-513.

Barro, Robert J. and Xavier Sala-i-Martin (2003) Economic Growth, Second Edition, MIT Press.

Baxter, Marianne. (1992), "Fiscal Policy, Specialization, and Trade in the Two-sector Model: The Return of Ricardo?” Journal of Political Economy 100, 713-44. 
Bianconi, Marcelo, (1995) “On Dynamic Real Trade Models”, Economics Letters, 47, 47-52.

Brecher, Richard A., Zhiqi Chen, and Ehsan U. Choudhri (2002) “Absolute and Comparative Advantage, Reconsidered: The Pattern of International Trade with Optimal Saving” Review of International Economics, 10, 645-656.

Brock, Phillip.L. and Stephen. J. Turnovsky, (1993) "The Growth and Welfare Consequences of Differential Tariffs”, International Economic Review 34, 765-794.

Caliendo, L (2009) “On the Dynamics of the Heckscher-Ohlin Theory”, Department of Economics, University of Chicago.

Chatterjee, P. and M. Shukayev (2012) "A Stochastic Dynamic of Trade and Growth: Convergence and Diversification”, Journal of Economic Dynamics \& Control 36 416432.

Chen, Zhiqi (1992) “Long-run Equilibria in a Dynamic Heckscher-Ohlin Model” Canadian Journal of Economics 23, 923-43.

Davis, Donald R. and David E. Weinstein (1998) “An Account of Global Trade,” NBER Working Paper 6785.

Dixit, Avinash and Victor Norman (1980), Theory of International Trade: A Dual, General Equilibrium Approach, Cambridge, MA: Cambridge University Press.

Eaton, Jonathan (1987) “A Dynamic Specific-Factors Model of International Trade”, Review of Economic Studies, 54, 325-338.

--(1988) “Foreign-Owned Land”, American Economic Review, 78, 76-88.

Fedotenkov, Igor, Bas van Groezen and Lex Meijdam (2014) “Demographic Change, International Trade and Capital Flows,” Open Economies Review 25, 865-883.

Harrigan, James, (1997) “Technology, Factor Supplies and International Specialization: Estimating the Neoclassical Model," American Economic Review 87, 475-94.

Hu, Yunfang, Kazuo Nishimura, and Koji Shimomura (2006) "Dynamic Three Factor Models of International Trade” Asia-Pacific Journal of Accounting and Economics 13, 73-85. 
-----------(2008) “Specific Factor Models and Dynamics in International Trade,” in Sugata Marjit and Eden S. H. Yu (eds) Contemporary and Emerging Issues in Trade Theory and Policy (Emerald Publishers, Bingley, UK), 191-207.

Komiya, Ryutaro, (1967) “Non-Traded Goods and the Pure Theory of International Trade,” International Economic Review 8, 132-52.

Jones, Ronald W. (1971) “A Three-Sector Model in Theory, Trade, and History,” in Bhagwati, J.N., R.W. Jones and J. Vanek (eds.) Trade, Balance of Payments and Growth, (North-Holland Publishing Company, Amsterdam).

Joseph, Francois, and Clinton R. Shiells (2008) “Dynamic Factor Price Equalization and International Convergence” Johannes Kepler University of Linz, Working Paper No. 0820.

Kaneko, A. (2006) “Specialization in a Dynamic Trade Model”, International Economic Journal 20, 357-368.

Laitner, John (2000) “Structural Change and Economic Growth” Review of Economic Studies 67, 545-561.

Mountford, A. (1998) “Trade, Convergence and Overtaking”, Journal of International Economics 46, 167-182.

Neary, Peter, 1978, “Short-Run Capital Specificity and the Pure Theory of International Trade”, Economic Journal 88, 488-512.

Oniki, Hajime, and Hirofumi Uzawa (1965), "Patterns of Trade and Investment in a Dynamic Model of International Trade,” Review of Economic Studies 32, 15-38.

Sen, Partha (2013) "Capital Accumulation and Convergence in a Small Open Economy” Review of International Economics 24, 690-704.

--------------(2015) “Uncertain Lifetimes and Convergence in a Two-country HeckscherOhlin Model” Mathematical Social Sciences 78, 14-20.

Stiglitz, Joseph E. (1970) “Factor Price Equalization in a Dynamic Economy” Journal of Political Economy 78, 456-88. 
Tadesse, Bedassa and Roger White (2010) “Does Cultural Distance Hinder Trade in Goods? A Comparative Study of Nine OECD Member Nations,” Open Economies

Review 21, 237-261.

Trefler, Daniel, (1993) "International Factor Prices: Leontief Was Right!" Journal of Political Economy 111, 961-87.

—(1995) “The Case of Missing Trade and Other Mysteries,” American Economic Review 85, 1029-46.

Ventura, Jaime (1997) “Growth and Interdependence,” Quarterly Journal of Economics 112, 57-84.

Woodland, Alan (1982) International Trade and Resource Allocation, (Amsterdam) North Holland.

i The world economy, of course, is a closed economy and hence a decline in the return to capital accompanies any accumulation of capital.

ii It is not even a candidate to explain trade between similar economies or intra-industry trade.

iii See Bardhan (1965), Oniki and Uzawa (1965) and Stiglitz (1970) for early contributions with saving being a constant proportion of income. Stiglitz (1970) also considers optimal savings but with the rate of time preference differing between economies. Woodland (1982) uses duality and sketches a dynamic model.

iv For a discussion of finite lives in dynamic trade models, see e.g. Bajona and Kehoe (2006-who have a many-period overlapping generations models, (they also discuss capital flows), Bianconi (1995) who has a two period overlapping generations structure and Kaneko (2006) with a continuous time uncertain lifetimes structure.

${ }^{v}$ Below we will see that tampering with this assumption (of only two factors that are mobile across the two sectors) that will result in very different predictions.

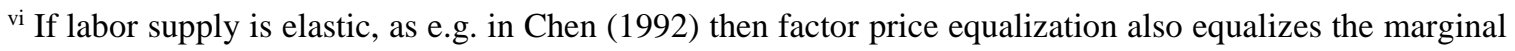
utility of leisure.

vii This relies on the evidence on the factor content of trade (Trefler (1993), (1995), Davis and Weinstein (1998)) and on the pattern of production (Harrigan (1997)).

viii The case of uniform Hicks-neutral superiority has received some empirical support from Trefler (1995) and Davis and Weinstein (1998).

ix For the US, all private land constituted 31 percent of total wealth in 1900 and 16 percent in 1958 . For the UK, it was 55 percent in 1798, 18 percent in 1885 and 4 percent in 1927. These figures are taken from Laitner (2000).

${ }^{x}$ A small open economy model is discussed in Sen (2013). In a small open economy model factor-price equalization follows-in our two-country model, this happens only in the steady state. 
xi See Arnold and Tepl (2015), Fedotenkov, van Groezen and Meijdam (2014), and Tadesse and White (2010).

xii Thus there is no need to identify one of the specific factors as land and other as labor, as is done below. I do this to fix ideas. Later on (in section 3) I give other interpretations. Clearly, the framework is richer than the limited interpretations given in this paper.

xiii Chen (1992) and Atkeson and Kehoe (2000) are examples. A previous version of our paper used this specification.

xiv Ventura (1997), Chaterjee and Shukayev (2012) and Francois and Shiells (2008) use this structure. Atkeson and Kehoe (2000) discuss this briefly.

${ }^{x v}$ See Brecher, Chen and Choudhri (2002) and Bajona and Kehoe ((2006), (2010)) for this structure.

xvi The specific factors $\mathrm{L}$ and $\mathrm{M}$ could be thought of as two kinds of labor. The interpretation that suits the analysis in section 2 is to think of $\mathrm{L}$ as labor and $\mathrm{M}$ as some endowment of fruits. In section 3.2, we introduce the valuation of the trees that bear these fruits (as in Eaton (1987), (1988)). In the earlier dynamic specific factors models, the capitals in the sectors were specific in the short run, while labor was mobile across sectors (Neary (1978)). In the long run, capital was also mobile across sectors, and the model collapsed into the familiar Heckscher-Ohlin model.

xvii Where there is no chance of confusion, we do not explicitly write the time index.

xviii Constant growth rates for $\mathrm{L}$ and $\mathrm{M}$ can easily be incorporated, as can exogenous technical progress. xix Note, while it would be interesting to look at an internationally mobile factor whose return is equalized internationally, such an assumption with free trade in the two intermediates and constant returns to scale would make all factor prices determined internationally. It would be possible to pursue this with one intermediate being non-traded and/or decreasing returns to scale technologies.

${ }^{x x}$ This is essentially reproducing the analysis of Dixit and Norman (1980), chapter 5.

xxi Since there is no borrowing or lending internationally, capital is the only store of value. If one of the specific factors was, say, land, then savings would also be allocated to a change in the value of land-see section 3.2 below. In an overlapping context, this can be crucial (see Eaton (1987), (1988)).

xxii We are going to use the relationships given in the Appendix A.

xxiii Since capital is now used exclusively in the X sector, its accumulation causes the supply of the Y good to fall, causing excess demand for the latter good and its price to rise. This is the big difference in the details of this example over the set-up where capital was the mobile factor. Note that this does not change the stability of the model, or its (qualitative) dynamics.

xxiv The issue of land availability on the development path of a small open economy is discussed in Sen (2013). 